\title{
Methods of Landslide Detection using GIS and Remote Sensing Images
}

\author{
Payal Varangaonkar, S. V. Rode
}

\begin{abstract}
The most challenging and damaging natural disaster is the landslides around the mountainous terrain especially in the western and northern regions of India. The landslides lead to several damages in terms of socio-economic impacts, thus it gains significant researcher's attention since from the last two decades to study and early prediction of landslides. The automatic and accurate landslide detection and localization become essential to suppress the socio-economic impacts with help using sensing remote images \& Geographical Information System (GIS). Nowadays remote sensing images provide useful information combined with the GIS environment related to the spatial factors that are influencing the landslide occurrence. The fundamental prerequisite for the landslide prediction using GIS is landslide inventory. In India, the satellite images collected using remote sensors such as LANDSAT ETM+, ASTER, IRS P6, etc. to form the landslide information over the parameters like aspect, slope, drainage density, relative relief, etc. Thus using the remote sensing images, the monitoring of landslide introduced. The landslide prediction using the remote sensing images however suffered from the various challenges. This paper presents the systematic review of various landslide prediction and localization methods using the remote sensing images and GIS information regardless of the study areas. The comparative analysis and the current research challenges for designing the automated landslide detection framework discussed based on the literature review.
\end{abstract}

Keywords: GIS, landslide detection, landslide localization, remote sensing images, image processing.

\section{INTRODUCTION}

The landslide frequently occurs in mountain terrain. As the rock has been breaking up and decomposed during the weathering process, the material that is weathered is soaked with water or rain which may lead the slide down because of gravity. This sudden downward slide of rock debris is known as landslide condition. On any terrain, a landslide occurs in the presence of the right environment of moisture, soil, and slope angle. Alongside regular states of topography surface of the earth, the avalanches help to dregs and redistribute soil in a procedure that can be in sudden falls or moderate mudflows, garbage streams, earth breakdown, slant

Revised Manuscript Received on December 30, 2019.

* Correspondence Author

Payal Varangaonkar*, Ph.D Scholar, Department of Electronics and Telecommunication, Sipna college of Engineering and Technology, Amravati, India. Email: payal.varangaonkar@gmail.com

Dr. S. V. Rode, Department of Electronics and Telecommunication, Sipna college of Engineering and Technology, Amravati, India. Email: sandeeprode30@gmail.com

(C) The Authors. Published by Blue Eyes Intelligence Engineering and Sciences Publication (BEIESP). This is an open access article under the CC BY-NC-ND license (http://creativecommons.org/licenses/by-nc-nd/4.0/) breakdown, and so on. The appearance of avalanches is particularly evident in geodynamic delicate belts for example zones and regions now and again shook by tremors and changed by other neotectonic activities [1]. In India, there are a few such areas where the continuous avalanches happening, e.g., the Darjeeling Himalaya recorded over 20,000 avalanches in a single day is a most defenceless belt of the Himalayan range. Around 30,000 people groups were lost their lives in 1968 in the same region. According to the examinations, it is noticed that the key parameters that start the mass development are (1) considerable and preceded with precipitation (2) cutting and profound gaps on the incline for development of building, streets, trench, and mining without appropriate transfer of flotsam and jetsam, and (3) quake stuns and tremors. Further, it is likewise seen that outrageous powers following up on inclines are: (a) weight of the material structure the slant for example rocks, soils, vegetation and man-made structures which act descending, and (b) the sheer quality of the materials acting in the potential slip planes [2]. Water isn't just the chief reason for rock enduring giving self cohesion less and flexible materials yet additionally the main object of mass development. It decreases the stones in sheer quality. Therefore for any avalanche, the key main thrust is identified with the gravitational power and mass development will be relative to the slope slant point.

Detection and localization of such landslide in such regions are essential to reduce or control the effects of landslide hazards. Conventionally in many regions of India, landslide prediction is performed costly procedures such as monitoring, surveying, soil testing, etc. These costly solutions are not feasible in the Indian rural regions with less available resources. Therefore, researchers focused on introducing the cost-effective and simple approach for continue assessing the landslide regions where the slope stability monitoring performs to check if the weather there is a possibility of a landslide in that particular region [3]. This is possible by using remote sensing images and GIS information. Many researchers focused on using remote sensing information using GIS for the landslide prediction and localization. Such a method not only brings automation but also saves the costs incurred in conventional techniques [4]. Various environmental tasks are solved by using remotely sensed data. The remote sensing approach therefore used as an effective way in investigation and monitoring of natural hazards like landslide as well as environmental planning. From the remote sensing information concerning landslide, the terrain information like geology, land cover, drainage, and geomorphology can be delivered and updated for the human interference quantification on the surface of the earth [5]. 
The GIS is an automated computer-based technology that acquires such remote sensing data from the landslide regions, performs the manipulation, transformation, analysis, modeling and prediction based on the spatial data processing. Thus it gains significant attention in the domain of remote sensing images based landslides detection and localization.

The remote sensing images used in many studies for the landslide prediction or detection or localization using the various image processing operations and machine learning methods. The change detection based on the pre and post landslide images performed using various methods such as thresholding, binary temporal methods, texture analysis, etc. However, all such solutions suffered from significant challenges related to scalability, accuracy, and efficiency. This motivates us to present the systematic study of all such methods introduced during the last two decades and study them comparatively according to the above challenges. This research focused on presents the review of remote sensing \& the basis of GIS landslide prediction or localization techniques to estimate the current research challenges. Section II presents a review of such methods. Section III presents the comparative study of reviewed recent techniques to justify the proposed solutions. Section IV presents the results of reviewed methods. Section V presents the discussion of current research challenges based on comparative study and results. Finally in VI presented conclusion \& future work.

\section{LITERATURE REVIEW}

As the name indicating, the objective of this section is to present the study of various landslide monitoring or detection approaches that are reported from 2007 onwards till to present 2019. We systematically progressively disclosed each study during this section.

In [6], the author proposed the method of maximum likelihood for classification with positive preliminary outcomes. The segmented the remote sensing image into a landslide as well as non-landslide areas carried with the use of a double threshold method in sequence using a histogram-based thresholding method. They also used the filtering approach for identified blobs basis on shape \& geomorphologic features that allow eliminating counterfeit areas.

In [7], the author introduced the approach for landslide features detection in rock masses using the remote sensing approach. The author introduced the GIS analysis in which they computed elementary features of pixels and whole images resembling various landslides typologies and besides the Kolmogorov-Smirnov coefficient to determine the association among movements and images. The texture filters designed to produce greater values in landslides zones allow the distinction between other land-uses and landslides.

In [8], a survey on remote sensing information application for the landslide monitoring presented along with their techniques and challenges. In the end, the author concluded that Landslide prediction remains complex and challenging even with ground monitoring techniques.

In [9], they introduced the novel solution for recognizing earthquake-triggered landslides spatial distribution by analysis after-event nature differences. They used pre and post-landslide images acquired from remote sensing over the same study area. They computed the radiometric normalization and geometric correction for producing every image vegetation index. Finally, the process of image difference computation applied to detect the change and produce the landslide map.

In [10], another image processing based landslide change detection approach presented. They developed and evaluated methods for change detection over the digital photographs of Tessina landslide in Italy. The various thresholding methods are evaluated as well as different filters used to remove the undesirable residual clutter from the threshold difference image.

In [11], the author presented a remote sensing-based approach for the large landslides inventory and photo-interpretation, analysis of determinant factors, movements stereo-plotting, and texture analysis based automotive landslide detection.

In [12], the author designed an approach to perform landslide prediction in the optical satellite collected images. The dataset is collected with STOT5 images settings of $5 \mathrm{~m}$ high resolution, posting of $30 \mathrm{~m}$ united with coarse interpretation. They received the benefits of using the multi-temporal sensor images for change detection according to the radiometric differences after well-defined precise co-registration/orthodox-rectification.

In [13], the systematic study presented by the author that shows the mapping of landslide hazard and its monitoring using the remote sensing approaches in combination with GIS by considering Indian study area in Himalaya region.

In [14], the research on landslide risk assessment based on GIS information presented. The author considered the study area for this research is Chamoli-Joshimath from the Himalaya region. Rather than working on remote sensing images, they collected the satellite data, rainfall data, field observations, etc. for study. However, this leads to the lack of sufficient evaluations and a non-effective approach for risk assessment of landslide.

In [15], remote sensing image processing based technique introduced for landslide detection. They introduced a combined strategy including object-oriented image analysis (OOIA), case-based reasoning (CBR) method, and genetic algorithm (GA). The landslide detection frameworks consist of three main phases such as (1) processing of image, (2) multi-scale image segmentation and features optimization, and (3) landslides detection.

In [16], another approach similar to [15] introduced for landslide detection. They designed the semi-automatic framework using the two machine learning methods and features selection approach over the Three Gorges of China area. Their category consequences concluded that (1) holes inclusion encompassed by way of the body of landslide, (2) remote segments elimination, and (3) closed envelope curves illustration for landslide targets by hand-operated digitizing technique. In [17], the writer investigated the far-flung sensing can provide to promote a quantitative landslide danger analysis at a geographical scale under the situation of data inadequacy. 
They did landslide susceptivity and risk assessment based derived from a 30-12 month's time series of satellite TV for pc faraway sensing information the usage of an automated category technique. However, the drawback of this technique is that the landslide hazard temporal factor can only be assessed if a multi-temporal stock is to be had.

In [18], the latest automated framework of landslides detection the usage of multi-temporal faraway sensing imagery delivered. The patch-orientated distinction detection approach based totally at the Deep Convolution Neural Network (DCNN) technique designed for extracting place with an excessive exchange degree, and the use of Spatial-Temporal Context Learning (STCL) makes the most of temporal and spatial records of faraway sensing picks for the precise category of landslide areas. This multi-degree extraction and filtering frame encompasses eliminating the inappropriate areas and distinguishing the landslides constantly, and assuring top detection fee whilst reducing the false alarm charge. However, there may be a hassle with this method that a few landslide areas no longer included for landslides detection, hence greater robustness and accuracy improvement required.

In [19], some other current methods based totally on far-flung sensing snapshots brought. They used the pre and publish landslide COSMO-Sky Med photos to categorize the landslide areas on the Kii Peninsula. The capacity for landslide detection the use of backscattering coefficient difference and intensity correlation were investigated. Additionally, they evaluated the speckle-noise discount approach with varying window sizes. However, several other limitations of this study disclosed related to limited analysis, limited satellite data and related to different acquisition times of optical and SAR images which may lead the inaccurate detections.

In [20], the hybrid approaches introduced further for the landslide detection using two well know techniques such as susceptibility analysis and change detection thresholding. They presented a quantitative analysis of the method and claiming improved accuracy. But this work is limited to the pixel with low resolution, the higher resolution yet to address.

In [21], a very current study delivered for the landslide detection the usage of multi-scale photo segmentation and diverse machine mastering algorithms. They provided the consolidated approach for landslide detection consisting of item-primarily based picture analysis (OBIA) with different machines gaining knowledge of (ML) strategies together with a multilayer perception neural community (MLP-NN), random forest (RF), and logistic regression (LR). Before making use of the gadget studying strategies, the multi-scale segmentation approach brought. However, for effective and reliability both phase i.e. segmentation and classification required to optimization using relative mathematical and probability concepts.

In [22], another recent OBIA based proposed for the landslide detection by using LiDAR-derived data. They designed a framework consist of phrases such as digital elevation model (DEM) derivatives preparation, segmentation of multi-resolution, SVM based classification, and the post-processing for refinement in outcomes. However, the author concludes that using OBIA approach it on a multi-temporal landslide inventory that turned into

is still challenging tasks for agriculture landslide detection. The imprecise classification is related to restricted terrain visibility in forest areas \& absences of high-resolution DEM data while landslide study. Their approach failed to detect the landslide effectively and completely.

\section{Proposed Methodology}

The aim of this paper is to investigate the current progress of landslide detection and localization mainly using the image processing operations. This section presents the comparative analysis based on the recent works reviewed in the above section for the landslide prediction using the GIS and remote sensing images in terms of methodology, study area, evaluation parameters, etc. in table 1 below. This comparative study helps to estimate the current research problems (discussed in section IV) for the future proposed solutions.

TABLE-I: CoMPARATIVE ANALYSIS OF LANDSLIDE DETECTION METHODS

\begin{tabular}{|c|c|c|c|c|c|}
\hline $\begin{array}{l}\text { Ref. } \\
\text { No. }\end{array}$ & Year & Methodology & $\begin{array}{l}\text { Study } \\
\text { Area }\end{array}$ & $\begin{array}{l}\text { Parameters } \\
\text { of } \\
\text { evaluation }\end{array}$ & Type \\
\hline [15] & 2015 & $\begin{array}{l}\text { OOIA, GA, } \\
\text { multi-scale } \\
\text { image } \\
\text { segmentation, } \\
\text { features } \\
\text { optimization. }\end{array}$ & $\begin{array}{l}\text { Conghu } \\
\text { a, south } \\
\text { China. }\end{array}$ & $\begin{array}{l}\text { Sensitivity, } \\
\text { Specificity, } \\
\text { Accuracy, and } \\
\text { ROC. }\end{array}$ & $\begin{array}{l}\text { Semi-A } \\
\text { utomate } \\
\text { d. }\end{array}$ \\
\hline [16] & 2015 & $\begin{array}{l}\text { OBIA, } \\
\text { segmentation, } \\
\text { features } \\
\text { selection, } \\
\text { SVM, and } \\
\text { Random } \\
\text { Forest. }\end{array}$ & $\begin{array}{l}\text { Gorges } \\
\text { of } \\
\text { China. }\end{array}$ & $\begin{array}{l}\text { Classification } \\
\text { accuracy and } \\
\text { position } \\
\text { mismatch. }\end{array}$ & $\begin{array}{l}\text { Semi-A } \\
\text { utomate } \\
\text { d. }\end{array}$ \\
\hline [17] & 2017 & $\begin{array}{l}\text { Susceptibility } \\
\text { models, } \\
\text { multi-temporal } \\
\text { landslide. }\end{array}$ & $\begin{array}{l}\text { Souther } \\
\mathrm{n} \\
\text { Kyrgyz } \\
\text { stan. }\end{array}$ & $\begin{array}{l}\text { Frequency } \\
\text { ratio and area } \\
\text { under the } \\
\text { receiver } \\
\text { operating } \\
\text { characteristic. }\end{array}$ & $\begin{array}{l}\text { Semi-A } \\
\text { utomate } \\
\text { d. }\end{array}$ \\
\hline [18] & 2018 & $\begin{array}{l}\text { DCCN, STCL, } \\
\text { DEM, and } \\
\text { thresholding. }\end{array}$ & $\begin{array}{l}\text { Beichua } \\
\text { n, } \\
\text { Shenzh } \\
\text { en, } \\
\text { Zhouqu } \\
\text {, }\end{array}$ & $\begin{array}{l}\text { Detection } \\
\text { Probability } \\
\text { (DP), Quality } \\
\text { Percentage } \\
\text { (QP), and } \\
\text { Classification } \\
\text { Error (CE). }\end{array}$ & $\begin{array}{l}\text { Automa } \\
\text { ted. }\end{array}$ \\
\hline [19] & 2018 & $\begin{array}{l}\text { Backscattering } \\
\text { coefficient } \\
\text { difference, } \\
\text { intensity } \\
\text { correlation, } \\
\text { speckle } \\
\text { filtering, } \\
\text { thresholding, } \\
\text { and masking. }\end{array}$ & $\begin{array}{l}\text { The Kii } \\
\text { Peninsu } \\
\text { la, } \\
\text { Japan. }\end{array}$ & $\begin{array}{l}\text { F-measure, } \\
\text { precision, and } \\
\text { recall. }\end{array}$ & $\begin{array}{l}\text { Semi-A } \\
\text { utomate } \\
\text { d. }\end{array}$ \\
\hline [20] & 2018 & $\begin{array}{l}\text { Pixel-based, } \\
\text { OOIA, change } \\
\text { detection } \\
\text { based } \\
\text { thresholding } \\
\text { and landslide } \\
\text { susceptibility } \\
\text { analysis. } \\
\end{array}$ & $\begin{array}{l}\text { Jilin } \\
\text { Provinc } \\
\text { e in } \\
\text { China. }\end{array}$ & $\begin{array}{l}\text { Correctness, } \\
\text { Completeness } \\
\text { Quality, } \\
\text { Out-of-Bag } \\
\text { Error rate, and } \\
\text { ROC. }\end{array}$ & $\begin{array}{l}\text { Semi-A } \\
\text { utomate } \\
\text { d. }\end{array}$ \\
\hline
\end{tabular}

Published By: 
Methods of Landslide Detection using GIS and Remote Sensing Images

\begin{tabular}{|c|c|c|c|c|c|}
\hline [21] & 2019 & $\begin{array}{l}\text { OBIA, LR, RF, } \\
\text { MLP-NN, } \\
\text { Multi-scale } \\
\text { segmentation, } \\
\text { and DEM. }\end{array}$ & & $\begin{array}{l}\text { Object } \\
\text { Matching } \\
\text { Index (OMI) } \\
\& \quad \text { Object } \\
\text { Pureness } \\
\text { Index (OPI), } \\
\text { Kappa } \\
\text { Coefficient, } \\
\text { ROC, } \\
\text { F-measure, } \\
\text { precision, and } \\
\text { recall. } \\
\end{array}$ & $\begin{array}{l}\text { Semi-A } \\
\text { utomate } \\
\text { d. }\end{array}$ \\
\hline [22] & 2019 & $\begin{array}{l}\text { DEM, OBIA, } \\
\text { Multi-resolutio } \\
\text { n } \\
\text { segmentation, } \\
\text { classification, } \\
\text { and } \\
\text { post-classificat } \\
\text { ion processing. }\end{array}$ & $\begin{array}{l}\text { Outer } \\
\text { Carpath } \\
\text { ians } \\
\text { (Małop } \\
\text { olskie } \\
\text { A } \\
\text { municip } \\
\text { ality, } \\
\text { Poland) }\end{array}$ & $\begin{array}{l}\text { Overall } \\
\text { accuracy and } \\
\text { Kappa index. }\end{array}$ & $\begin{array}{l}\text { Semi-A } \\
\text { utomate } \\
\text { d. }\end{array}$ \\
\hline
\end{tabular}

From the above table, it is noticed that most of the methods are based on machine learning and thresholding approach for change detection and landslide prediction. The majority of recent works focused on a semi-automated approach with the limited set of datasets which leads to the challenges of scalability as well as the lower and higher pixel resolutions. Another interesting thing is that there is no recent work reported over the Indian landslides regions, as most of the works are from China. The key steps of remote sensing-based images are noticed as pre-processing, segmentation, features extraction/selection, and landslide detection either thresholding or machine learning methods.

\section{RESUlts ANAlysis}

This section presents the overall accuracy results of the methods reviewed and compared in above sections. Figure 1 and table 2 shows the landslides detection accuracy of various methods recently proposed. The results shows that the method proposed in [19] and [22] are having poor detection accuracy among all the methods. The approach recently introduced in [21] achieved the higher detection accuracy.

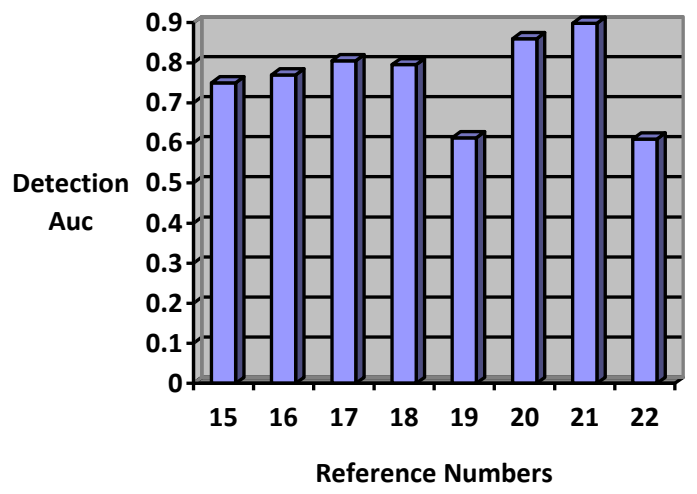

Figure 1: Landslide detection accuracy analysis.

\section{TABLE-II: ACCURACY RESULTS OF LANDSLIDES} DETECTION

\begin{tabular}{|c|c|}
\hline $\begin{array}{c}\text { Ref. } \\
\text { Number. }\end{array}$ & Accuracy \\
\hline 15 & 0.75 \\
\hline
\end{tabular}

\begin{tabular}{|l|l|}
\hline 16 & 0.77 \\
\hline 17 & 0.805 \\
\hline 18 & 0.795 \\
\hline 19 & 0.6124 \\
\hline 20 & 0.86 \\
\hline 21 & 0.898 \\
\hline 22 & 0.61 \\
\hline
\end{tabular}

\section{RESEARCH PROBLEM}

From the above literature and results, we noticed some of the research problems for effective landslide detection and localization using the remote sensing images such as:

- Lack of sufficient data and information of landslide areas especially in western and northern India.

- Inappropriate techniques to analyze landslide images, poor landslide assessment accuracies, and complex determination of landslide changes localization etc.

- Due to complex appearances nature work, this is challenging to get spatial regularities which are related to the land-slides and hence land-slides prediction and localization just using the artificial features or spatial information leads the poor results.

- Accuracy of landslides detection is poor still poor in recent works.

There is no work reported that considers the problem of landslide analysis in two stages like prediction and area localization so far.

\section{CONCLUSION AND FUTURE WORK}

The remote sensing methods used in landslide research based on different spectral and spatial resolution imagery have been introduced for the last three decades. The prediction of landslide using remote sensing images gained significant attention since from the last decade using the real-time images over the conventional techniques. This research shows reviews and observations of such methods for the detection of a landslide. We discussed the landslide detection techniques using remote sensing information from 2007 onwards. The comparative analysis to estimate the research problems is presented for the recent works at the end. For future works, there are several directions on which the framework landslide detection should be optimized by considering the research problems disclosed in this paper.

\section{REFERENCES}

1. Bolt, B.A., "Landslide Hazard, Geological Hazard”, Springer Verlag, New York, 150, 1975.

2. Beek, L.P.H.V., Asch, T.W.JV., "Regional assessment of the effects of land-use change on landslide hazard utilizing physically-based modeling," Natural Hazards, 31,289-304, 2004.

3. Saha, A.K., Gupta, R.P., Arora, M.K., "GIS-based landslide hazard zonation in the Bhagirathi (Ganga) Valley, Himalayas," International Journal of Remote Sensing, 23(2), 357-369, 2002.

4. Sakellariou, M.G., Ferentinou, M.D., "GIS-based estimation of slope stability," Natural Hazards Rev 2(1), 12-21, 2001.

5. Arora, M.K., Das Gupta, A.S., Gupta, R.P., “An artificial neural network approach for landslide hazard zonation in the Bhagirathi (Ganga) Valley, Himalayas," International Journal of Remote Sensing, 25(3), 559-572, 2004.

6. G. Danneels, E. Pirard and H. Havenith, "Automatic landslide detection from remote sensing images using supervised classification methods," 2007

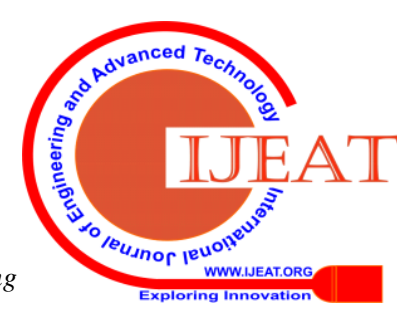


IEEE International Geoscience and Remote Sensing Symposium, Barcelona, 2007, pp. 3014-3017.

7. Castillo, Tomás \& Jiménez, J. \& Fernández, P. \& Hamdouni, R. \& Delgado, Jorge \& Irigaray, C. and Chacón, José, "Automatic detection of landslide features with remote sensing techniques in the Betic Cordilleras (Granada, Southern Spain)," The International Archives of the Photogrammetry, Remote Sensing and Spatial Information Sciences. XXXVII. 351-356, 2008.

8. Singhroy V., "Satellite Remote Sensing Applications for Landslide Detection and Monitoring," In Sassa K., Canuti P. (eds) Landslides Disaster Risk Reduction. Springer, Berlin, Heidelberg, 2009.

9. Xiaojun Yang, and Liding Chen, "Using multi-temporal remote sensor imagery to detect earthquake-triggered landslides", International Journal of Applied Earth Observation and Geoinformation, Volume 12, Issue 6 , 2010, Pages 487-495, ISSN 0303-2434.

10. Rosin, Paul and Barredo, José., "Remote Sensing Image Thresholding for Landslide Motion Detection," 2010

11. Pascale, Stefania \& Pastore, Vittoria \& Sdao, Francesco \& Sole, Aurelia \& Roubis, Dimitri and Lorenzo, Pietro., "Use of Remote Sensing Data for Landslide Change Detection: Montescaglioso Large Landslide (Basilicata, Southern Italy)," IJAEIS. 3. 14-25. 10.4018/jaeis.2012010102, 2012.

12. Lacroix, P., Zavala, B., Berthier, E., and Audin, L., "Supervised Method of Landslide Inventory Using Panchromatic SPOT5 Images and Application to the Earthquake-Triggered Landslides of Pisco (Peru, 2007, Mw8.0)," Remote Sens. 2013, 5, 2590-2616.

13. Rai, Praveen, Mohan, Kshitij and V.K.Kumra, " LANDSLIDE HAZARD AND ITS MAPPING USING REMOTE SENSING AND GIS," Journal of Scientific Research. 58. 1-133333, 2014.

14. Chaturvedi, Pratik \& Dutt, Varun \& Jaiswal, Brajesh \& Tyagi, Neetu \& Sharma, Sumit \& Mishra, Sp \& Dhar, Sunil \& Joglekar, Prakash., "Remote Sensing Based Regional Landslide Risk Assessment," International Journal of Emerging Trends in Electrical and Electronics 2320-9569. 10. 135-140, 2014

15. Dou, J.; Chang, K.-T.; Chen, S.; Yunus, A.P.; Liu, J.-K.; Xia, H.; and Zhu, Z., "Automatic Case-Based Reasoning Approach for Landslide Detection: Integration of Object-Oriented Image Analysis and a Genetic Algorithm," Remote Sens. 2015, 7, 4318-4342.

16. Li, X.; Cheng, X.; Chen, W.; Chen, G.; Liu, S., "Identification of Forested Landslides Using Lidar Data, Object-based Image Analysis, and Machine Learning Algorithms," Remote Sens. 2015, 7, 9705-9726.

17. Golovko, D.; Roessner, S.; Behling, R.; Wetzel, H.-U.; Kleinschmit, B., "Evaluation of Remote-Sensing-Based Landslide Inventories for Hazard Assessment in Southern Kyrgyzstan," Remote Sens. 2017, 9, 943.

18. Chen Z, Zhang Y, Ouyang C, Zhang F, and Ma J., "Automated Landslides Detection for Mountain Cities Using Multi-Temporal Remote Sensing Imagery," Sensors (Basel). 2018 Mar 9;18(3). PII: E821.

19. Tomohisa Konishi and Yuzo Suga, "Landslide detection using COSMO-SkyMed images: a case study of a landslide event on the Kii Peninsula, Japan,” European Journal of Remote Sensing, 51:1, 205-221, 2018.

20. Si, A.; Zhang, J.; Tong, S.; Lai, Q.; Wang, R.; Li, N.; Bao, Y., "Regional Landslide Identification Based on Susceptibility Analysis and Change Detection,” ISPRS Int. J. Geo-Inf. 2018, 7, 394.

21. Tavakkoli Piralilou, S.; Shahabi, H.; Jarihani, B.; Ghorbanzadeh, O.; Blaschke, T.; Gholamnia, K.; Meena, S.R.; Aryal, J., "Landslide Detection Using Multi-Scale Image Segmentation and Different Machine Learning Models in the Higher Himalayas," Remote Sens. 2019, 11, 2575.

22. Pawłuszek, K.; Marczak, S.; Borkowski, A.; Tarolli, P., "Multi-Aspect Analysis of Object-Oriented Landslide Detection Based on an Extended Set of LiDAR-Derived Terrain Features,” ISPRS Int. J. Geo-Inf. 2019, 8, 321.

\section{AUTHORS PROFILE}

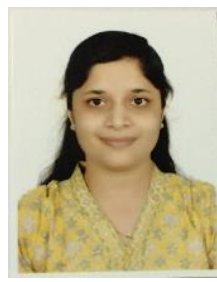

Payal Varangaonkar, PhD Scholar, Electronics and Telecommunication department, Sipna College of Engineering \& Technology, Amravati.

Membership:

1. Life Member -IETE The Institute of Electronics and Telecommunication Engineers.

2. Life Member - Life Member ISTE Indian Society for technical Education.

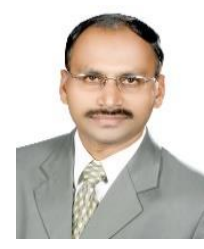

Dr. S V Rode, Professor, Electronics and Telecommunication department, Sipna College of Engineering \& Technology, Amravati.

1. Member, Institution of Electrical \& Electronics Engineers (IEEE)

2. Fellow, Institution of Electronics \& Telecommunication Engineers (FIETE),

3. Member Institution of Engineers, India (FIE),

4. Life Member, The Indian Society For Technical Education (ISTE) 